\title{
The Last Paper of Warren B. Hamilton
}

\section{Lawrence Hamilton}

Department of Sociology

University of New Hampshire

Geological Society of America Annual Meeting

Phoenix AZ

September 22, 2019

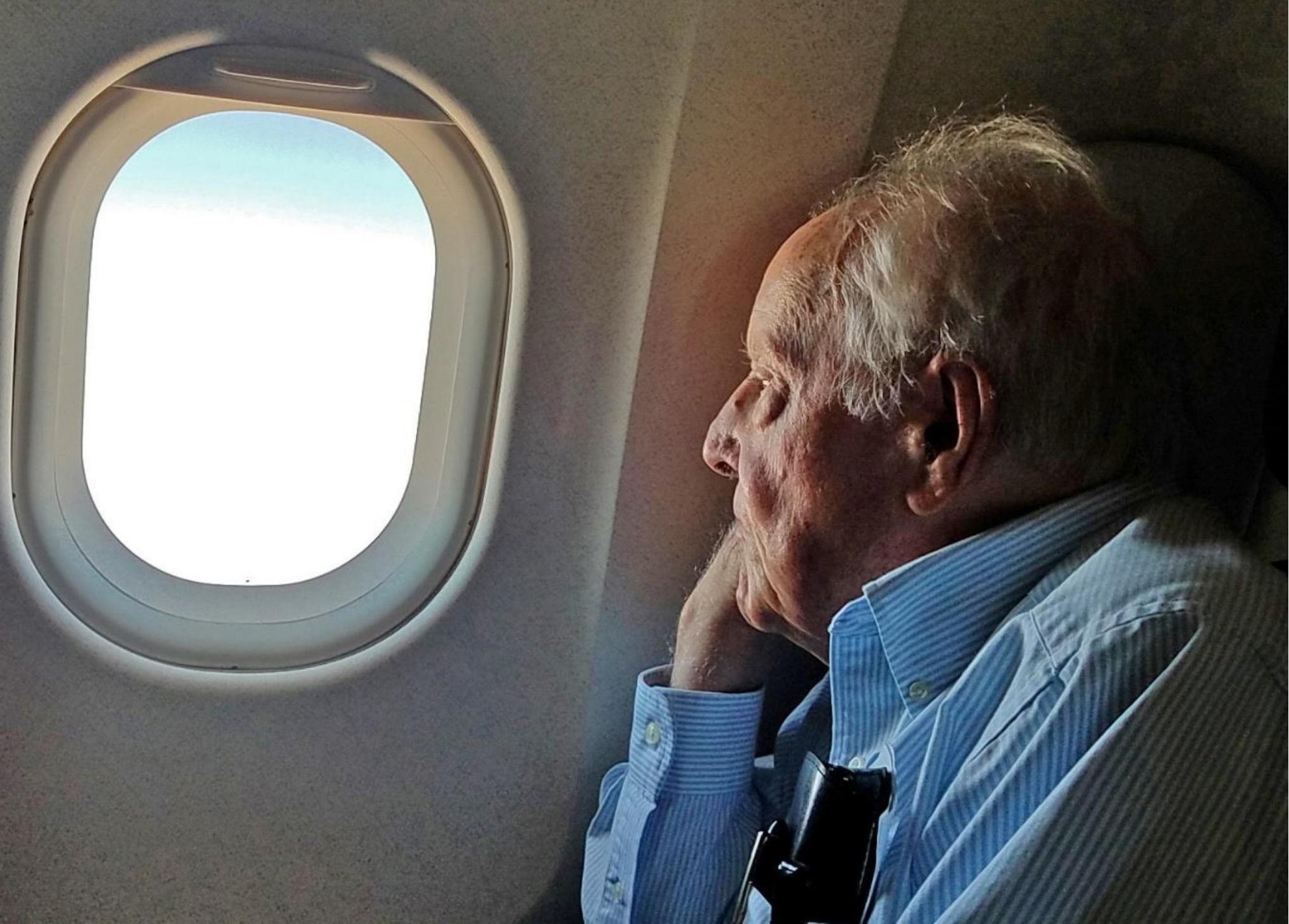


Over the last year of his life, Warren focused on writing a synthesis paper he viewed as the culmination of his career.

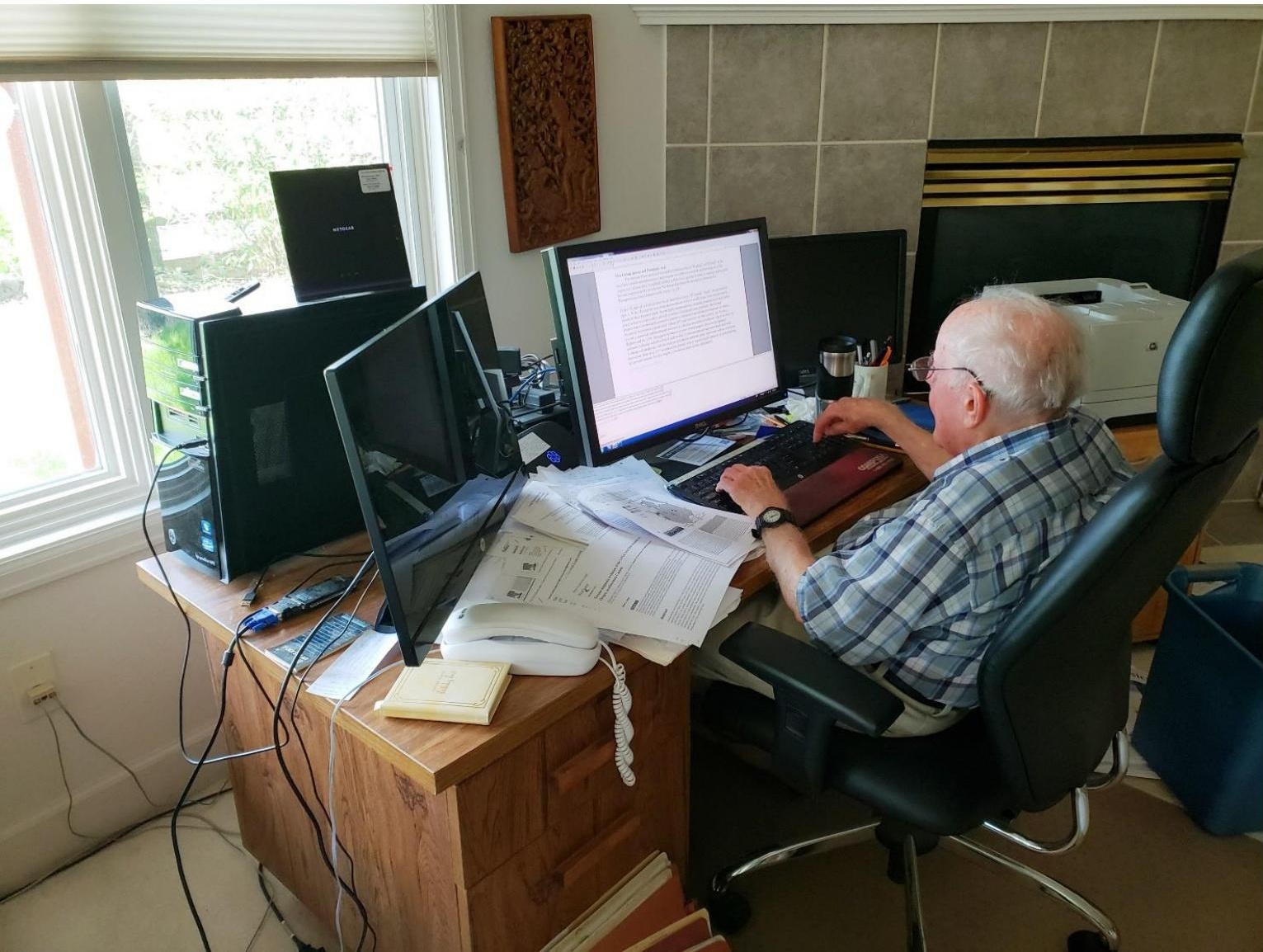

He knew this was a race against time. 
Time won that race, but just barely. When Warren passed away in October 2018, he left behind a 39,000-word manuscript, which he considered to be $95 \%$ complete.

Still, much was undone. The draft lacked an abstract or conclusion. Several sections consisted of just headings, or a few lines of notes. It had not been edited or reviewed.

Gillian Foulger took on the heroic task of bringing this work to publication. Keith Howard, Donna Jurdy, Anne Hofmeister, Robert Criss, Barbara John and Toby Rivers gave valuable assistance. Comments by James Natland and an anonymous reviewer helped to improve the final draft. 
Toward a myth-free geodynamic history of Earth and its neighbors Warren B. Hamilton ${ }^{\dagger, 1}$

Department of Geophysics, Colorado School of Mines, Golden, CO 80401, USA

"I recognize that my comments are outspoken. At the same time I have no illusion of personal infallibility." 
- Earth's Archean was the era of internally mobile crust. TTG crust formed by hydrous melting of mafic protocrust leaving dense, depleted, garnet-rich residue that delaminated and sank, beginning re-enrichment of the mantle. Archean granite and greenstone crust has no modern analogue.

- Proterozoic dynamics, driven by vertical variations in density, reflect the deposition and collapse of basins. Paleomagnetic data cast doubt on the existence of a strong dipole magnetic field at that time. Only in the late Proterozoic did a weak asthenosphere develop over which lithospheric plates could slide.

- The Phanerozoic has been the era of plate tectonics. Lithosphere motions documented by paleomagnetism suggest Earth's dipole magnetic field may have developed at $\sim 600 \mathrm{Ma}$. The Cambrian explosion in which most modern phyla evolved may have required its shielding against radiation. 
- In modern Earth, hinges migrate oceanward as subducting slabs sink to $660 \mathrm{~km}$ beneath overriding plates. Plate boundaries change radically, incompatible with plume-driven tectonics.

- Earth, Mars, Venus \& Moon fractionated by 4.5-4.4 Ga. Bombardment saturated surfaces with craters \& pools of impactmelted mafic protocrust that fractionated into layered igneous complexes.

- Mars, Venus \& Moon retain ancient, impacted surfaces. They lack asthenospheres or liquid cores, and cannot sustain plate tectonics.

- Variants of plume theory have been inappropriately exported to these planets. 
- Volatiles reached inner planets with icy bombardments starting $\sim 4.0-3.9$ Ga. Ocean remnants survived for 2-3 b.y. on Venus, and $\sim 1$ b.y. on Mars.

- Only Earth was internally hot \& active enough to circulate volatiles downward enabling hydrous melting, slow re-enrichment of the upper mantle and, at $\sim 600 \mathrm{Ma}$, plate tectonics and rapid biological evolution. 


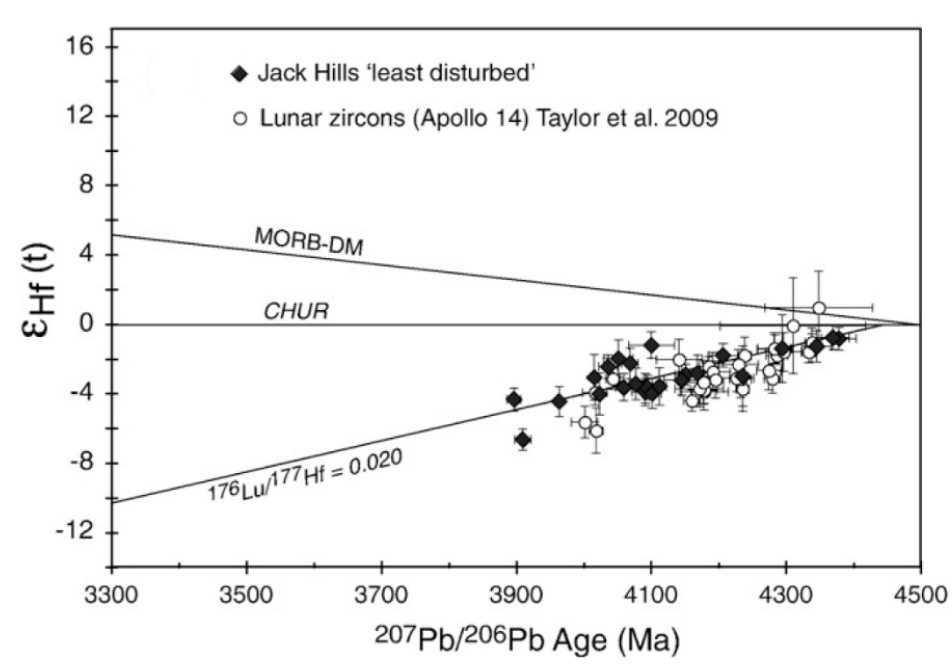

\section{These conclusions synthesize evidence from hundreds of studies, also new analysis of lutetium/hafnium systematics.}

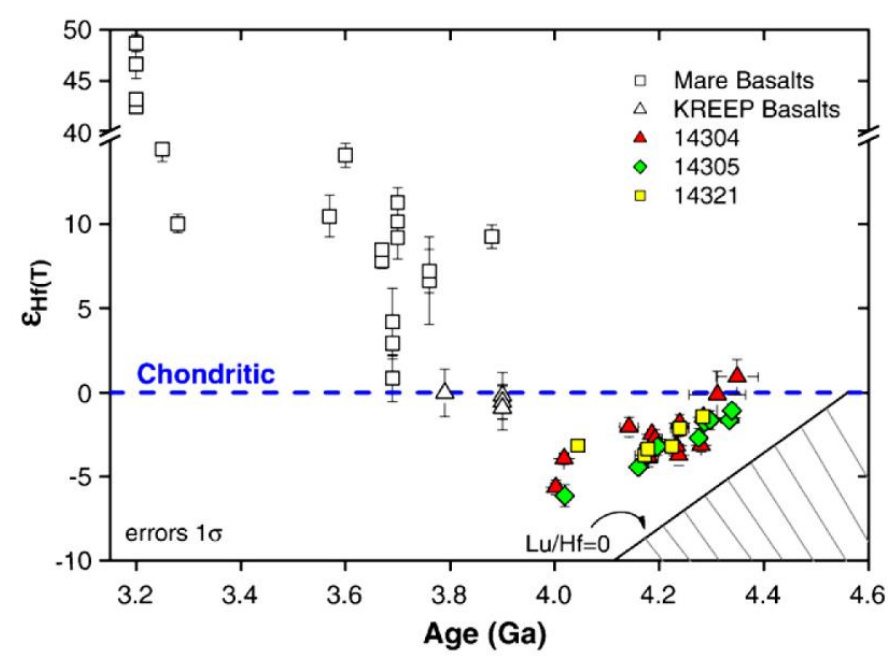

Earth, the Moon and Mars show Hf-isotopic evidence for similar histories of anhydrous very early fractionation.
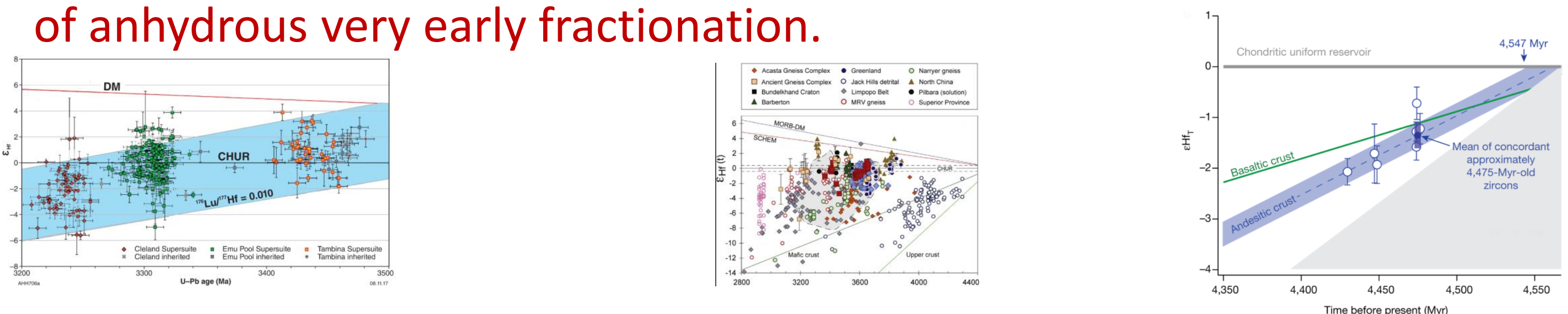

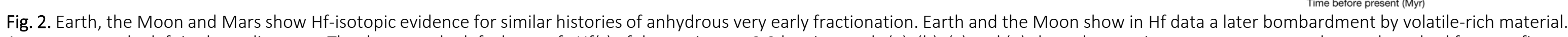

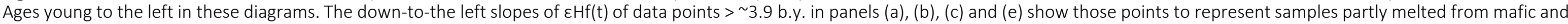

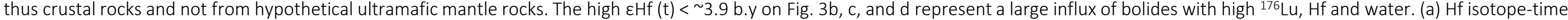

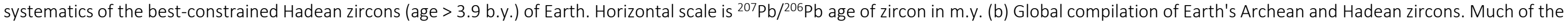

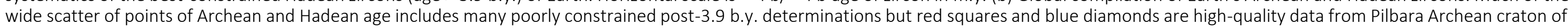

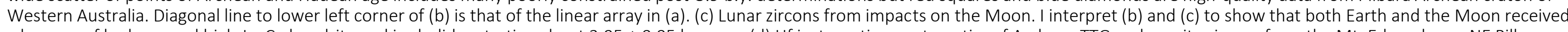

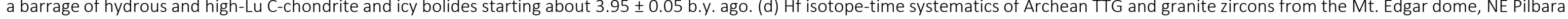

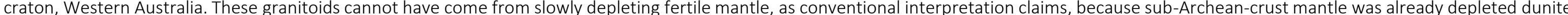

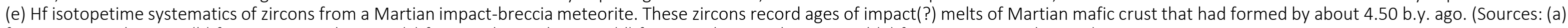
from Kemp et al., 2010, (b) from Kemp et al., 2015, (c) from Taylor et al., 2009, (d) from Gardiner et al., 2018 and (e) from Bouvier et al., 2018). 
They also draw heavily on Warren's own fieldwork around the world.

(a)

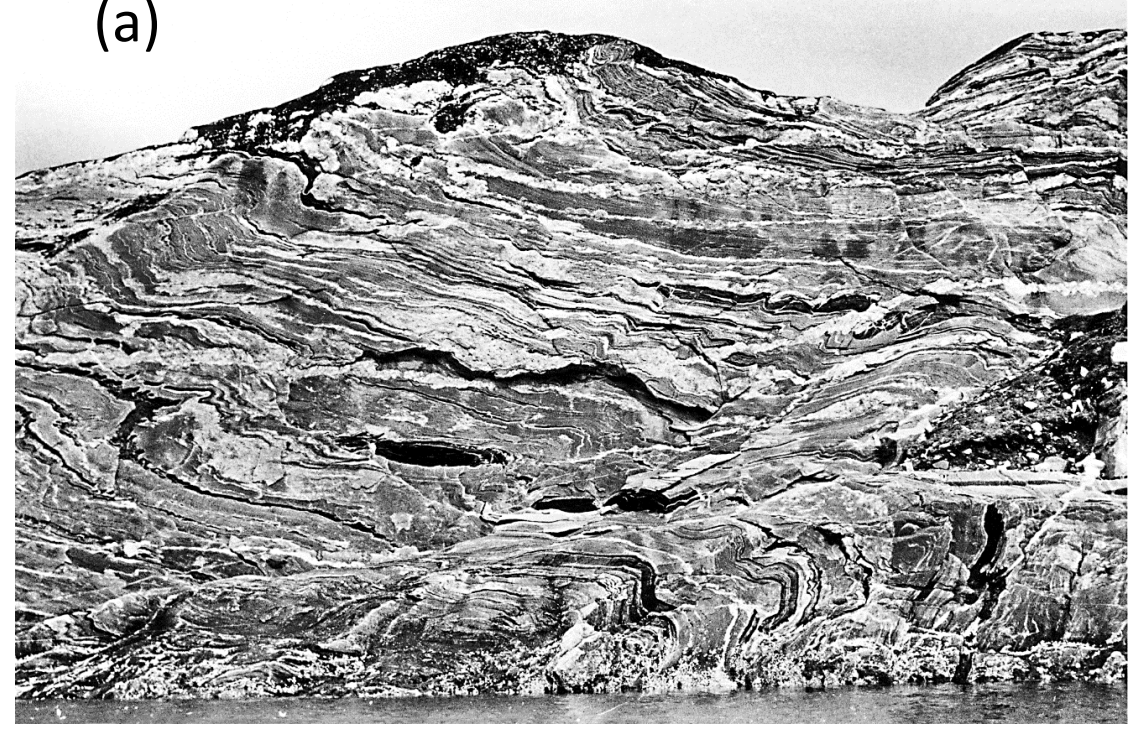

Much Archean TTG-dominated lower crust shows high mobility continuing for $\sim 1$ b.y.
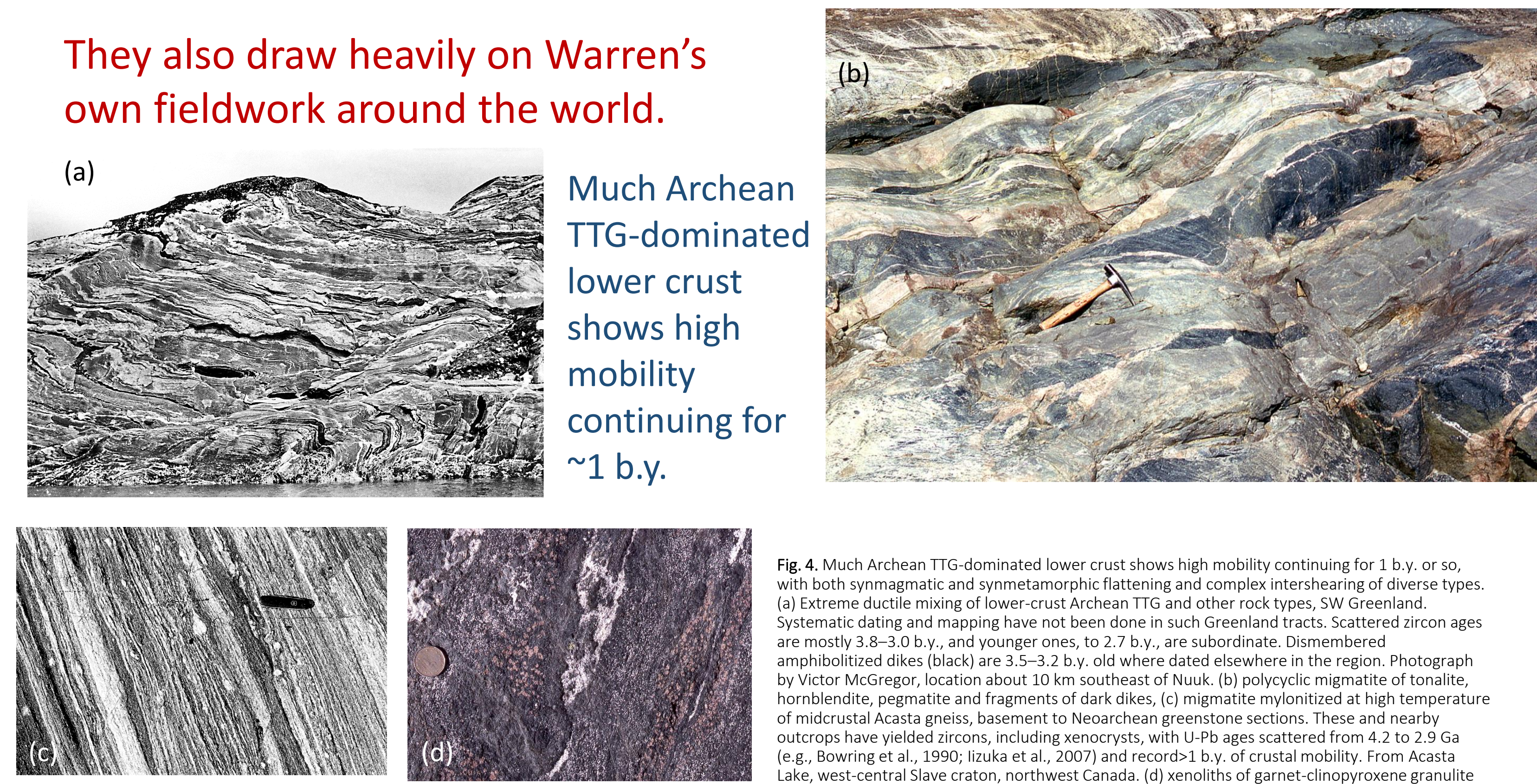

Fig. 4. Much Archean TTG-dominated lower crust shows high mobility continuing for 1 b.y. or so, with both synmagmatic and synmetamorphic flattening and complex intershearing of diverse types. (a) Extreme ductile mixing of lower-crust Archean TTG and other rock types, SW Greenland. Systematic dating and mapping have not been done in such Greenland tracts. Scattered zircon ages are mostly 3.8-3.0 b.y., and younger ones, to 2.7 b.y., are subordinate. Dismembered amphibolitized dikes (black) are 3.5-3.2 b.y. old where dated elsewhere in the region. Photograph by Victor McGregor, location about $10 \mathrm{~km}$ southeast of Nuuk. (b) polycyclic migmatite of tonalite, hornblendite, pegmatite and fragments of dark dikes, (c) migmatite mylonitized at high temperature of midcrustal Acasta gneiss, basement to Neoarchean greenstone sections. These and nearby outcrops have yielded zircons, including xenocrysts, with U-Pb ages scattered from 4.2 to $2.9 \mathrm{Ga}$ (e.g., Bowring et al., 1990; lizuka et al., 2007) and record>1 b.y. of crustal mobility. From Acasta Lake, west-central Slave craton, northwest Canada. (d) xenoliths of garnet-clinopyroxene granulite (possible protocrust densified by extraction of TTG melts?) and hornblendic garnet-free reaction rocks in basal TTG crust, at the eastern base of Proterozoic Kapuskasing uplift, Superior craton, Canada. Photos (b)-(d) by the author. 
Observations from space probes inform the planetary conclusions.

Mars global dichotomy - analogue for early Earth?

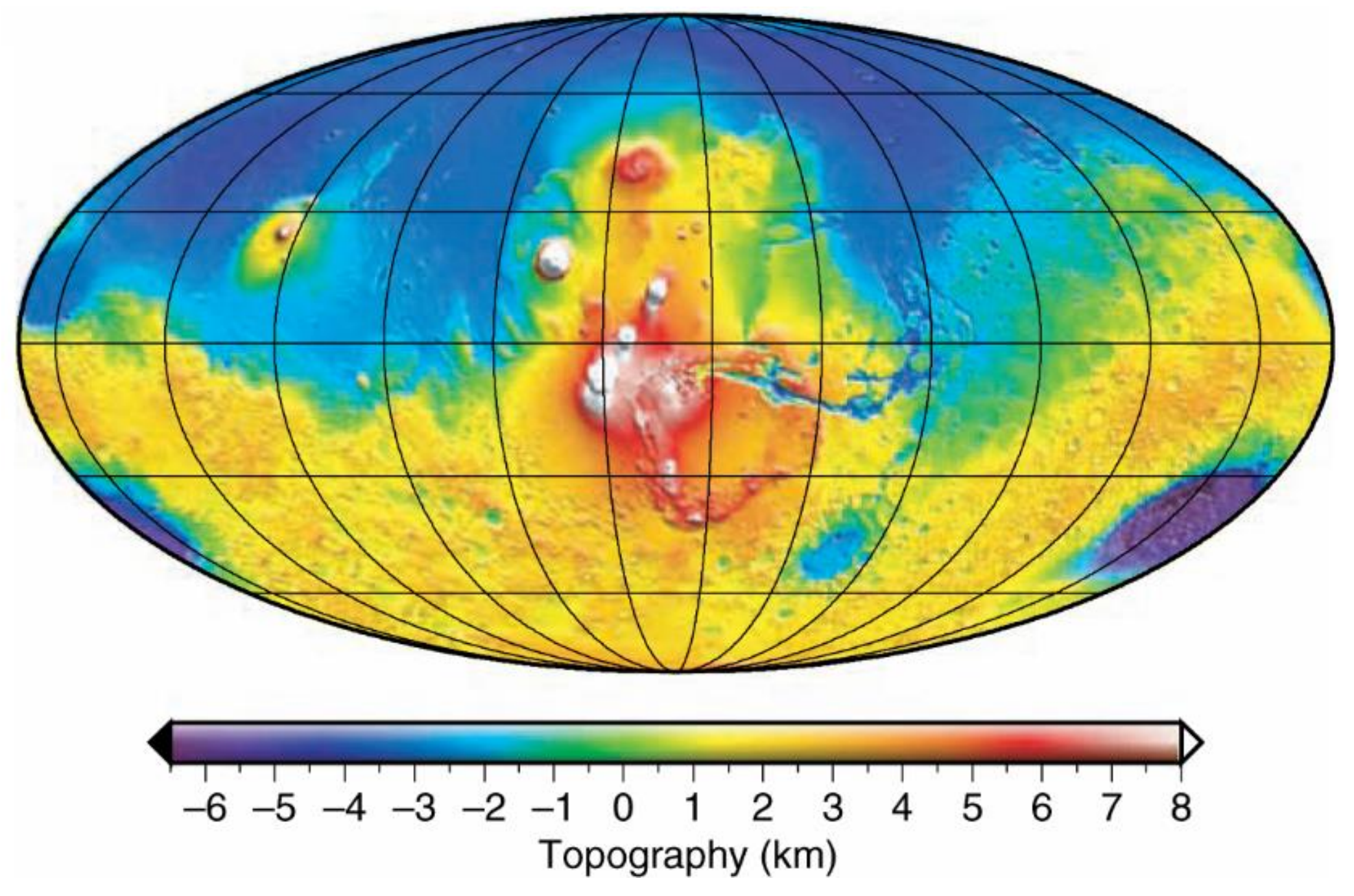

Fig. 7. Topographic map of Mars. The lower altitude

of the northern half of the planet compared with the southern half may be the product of a massive

impact during accretion.

Earth perhaps developed a similar bimodal

topography from loss of

the material that makes

up the Moon, by impact or

spinoff, during accretion.

Map by Wieczorek, 2007. 
First-order field observations do not support plume theories, instead suggesting that plate motions are driven primarily from the top down, as lithosphere cools \& sinks.
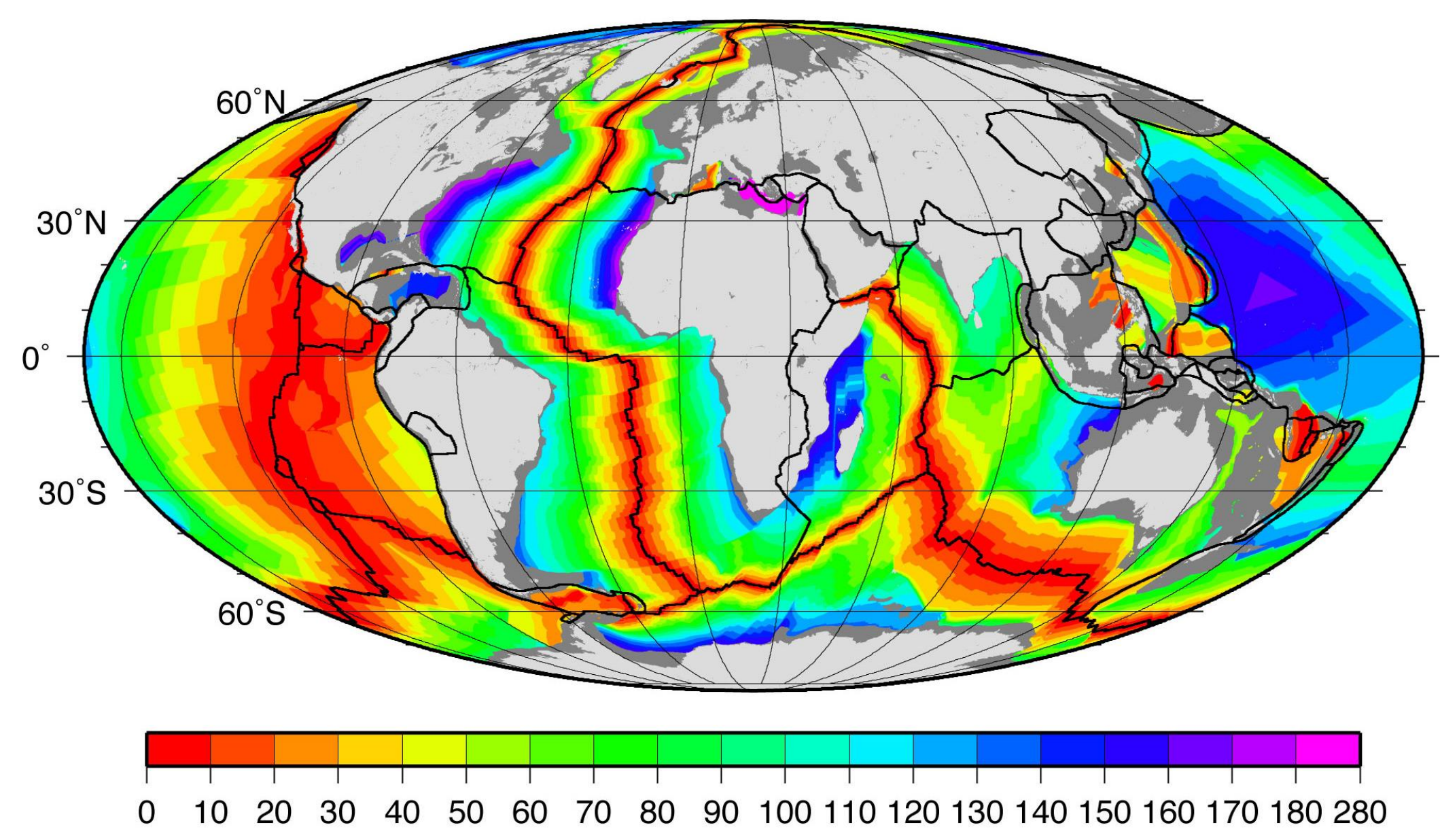

Age of Oceanic Lithosphere [m.y.]

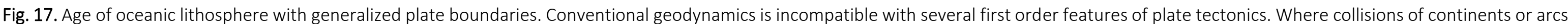

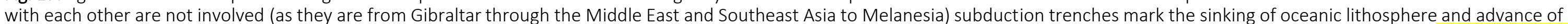

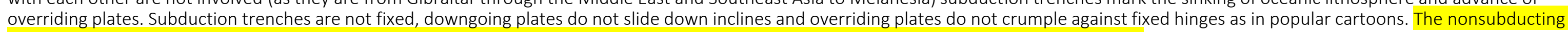

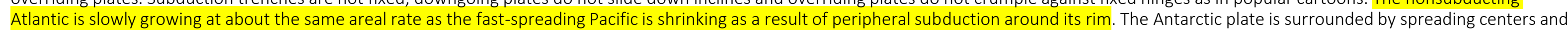

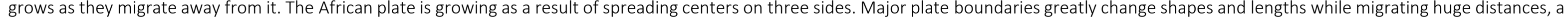

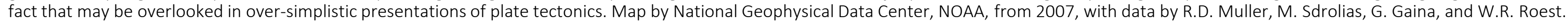


The 1970s conjectures of terrestrial plumes were exported to Mars and Venus. However, those planets are fundamentally different from Earth. They lack plate tectonics, so new rationales were developed - often contrary to geologic evidence.

Venus

topography

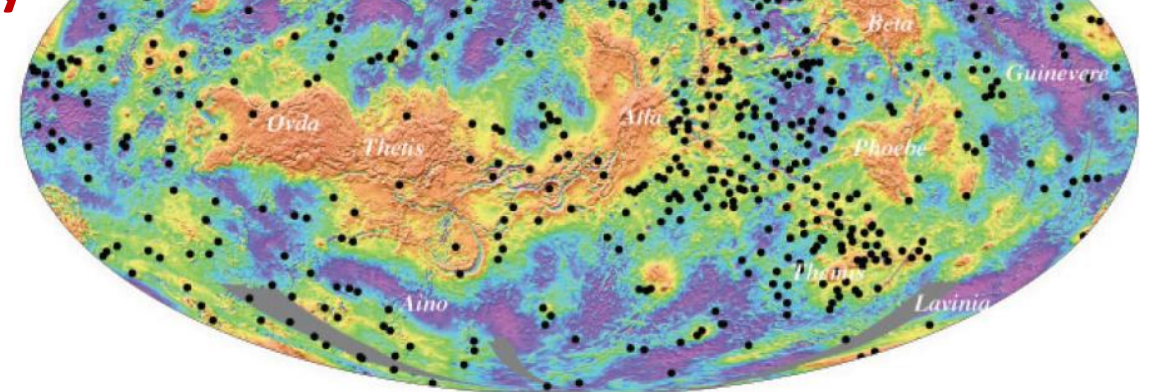

Venus

geoid

\section{B}

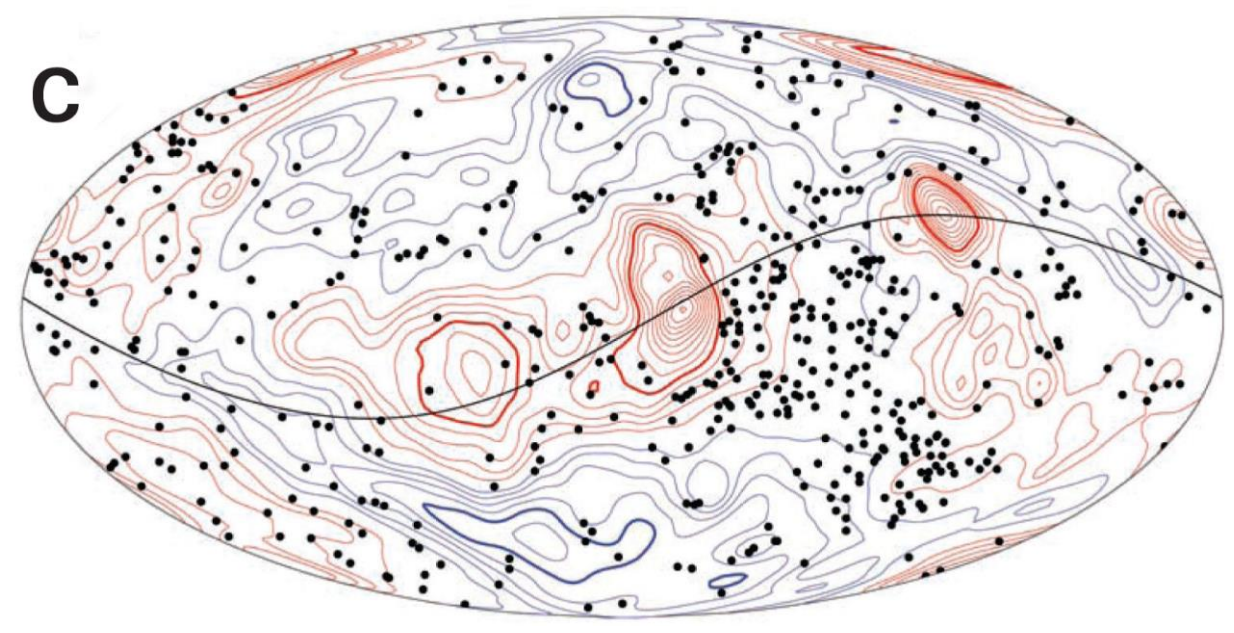

Earth geoid uncorrelated with topography

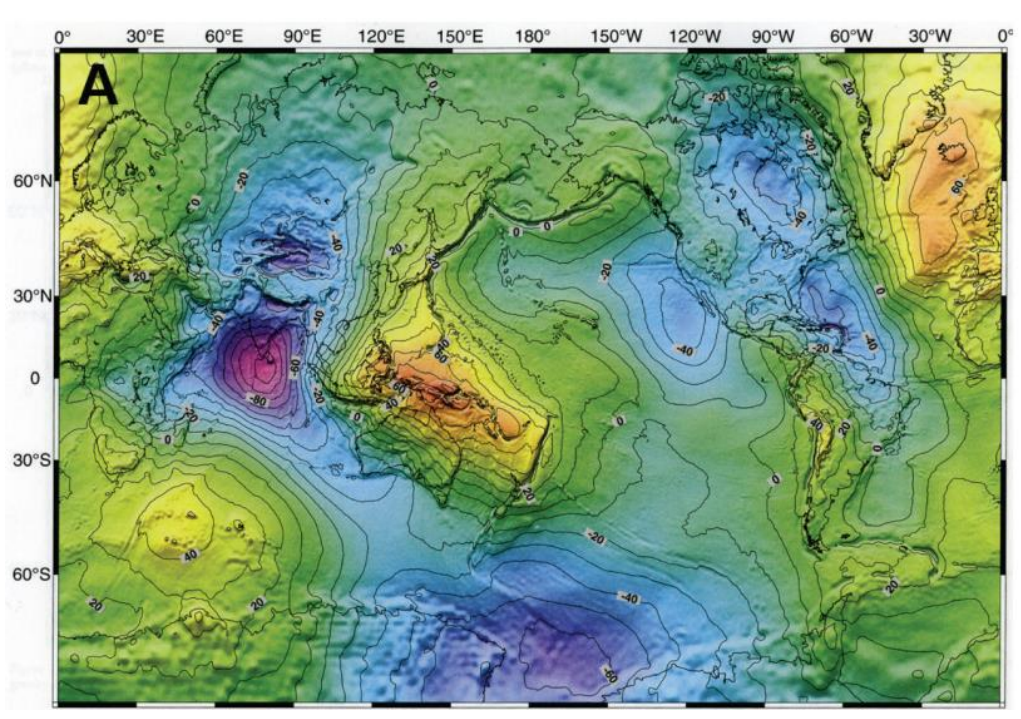

Fig. 29. Earth geoid compared to Venus topography and geoid. A, terrestrial geoid, 10m contours, blue and purple low, green/yellow/brown high. Earth's topography is mostly compensated isostatically at upper-mantle depths and shows almost no correlation with the geoid except at very short wavelengths. B, Venusian topography, and C, geoid correlate directly over a broad range of wavelengths. Thus, topography cannot be compensated primarily by earthlike variations in upper mantle structure and density. Venusian geoid height shown by $10 \mathrm{~m}$ contours, 0 not shown, red positive, blue negative; spherical harmonic degrees 2-30 are fully retained but a roll-off is applied to degrees 30-60. Venus maps are centered on the equator and longitude 180 . Dots on Venus maps mark the small proportion of large rimmed circular structures designated as "coronae" in conventional reports and assumed to be pushed up by plumes. Nearly all of the more abundant similar structures in lowland areas are omitted. A provided by David Sandwell, and B and C by Catherine Johnson, who also supplied the topographic altitude scale for B, corrected from that published by Johnson and Richards (2003). 
All photographs we have of Venus' surface appear to show flat, thinbedded, fine-grained sediments, not lava flows.

\section{Venera 14 , panorama B}

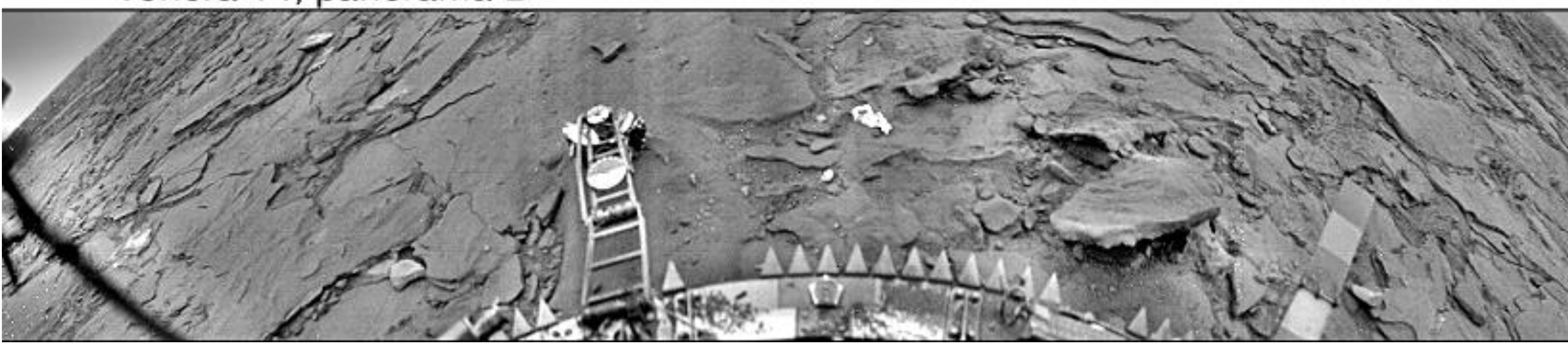

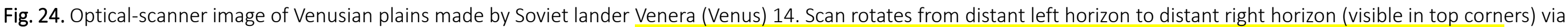

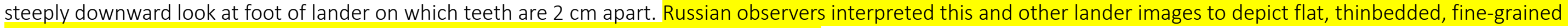

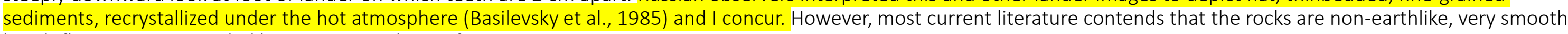
basalt flows. Image provided by Russian Academy of Sciences. 


\section{Magellan radar backscatter (A) poorly registers topography. Nadir-radar}

altimetry (B) reveals ancient landscape with 1,000s of sediment-filled craters.
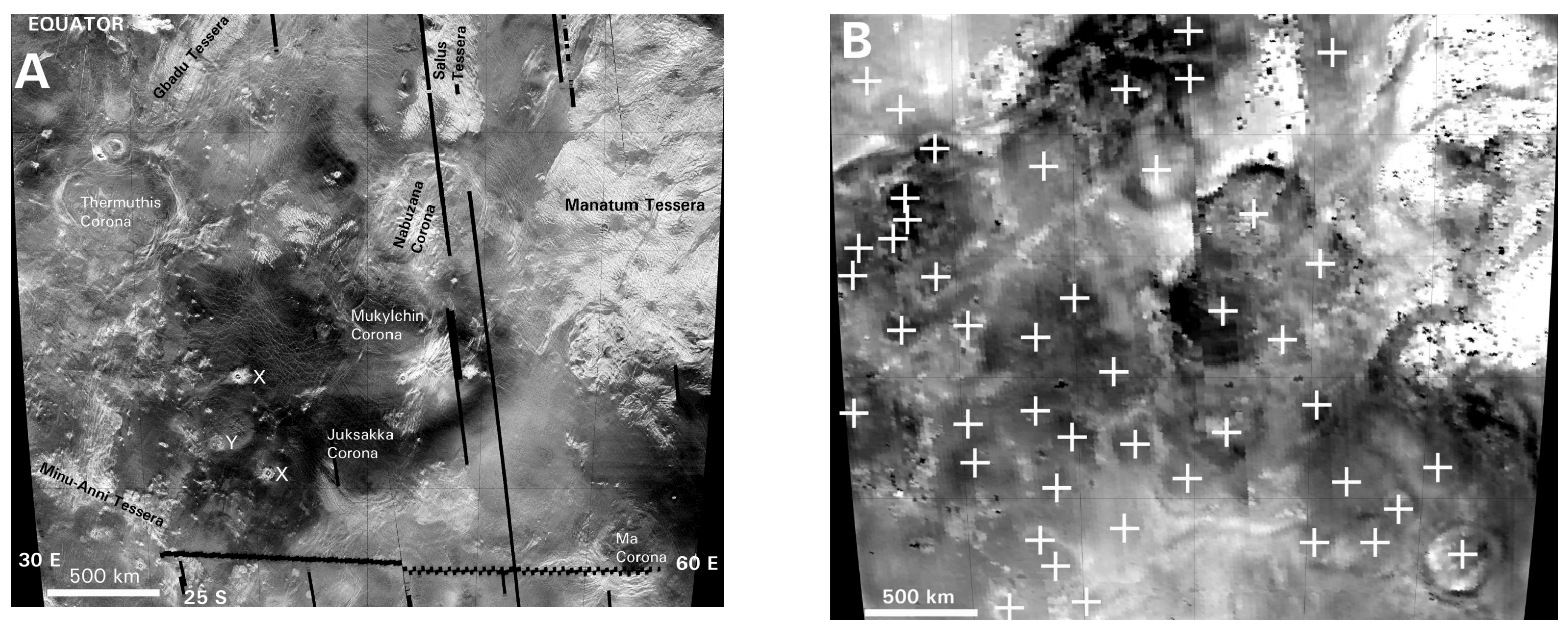

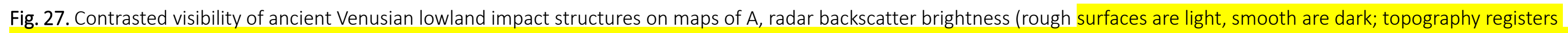

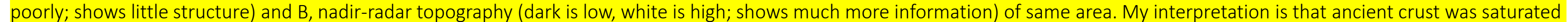

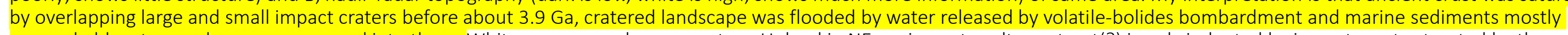

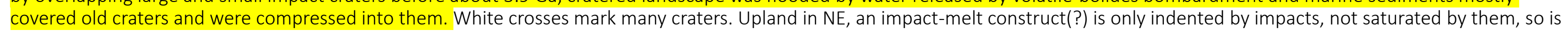
younger than plains basement. Magellan mosaics by USGS of area from $0^{\circ}$ to $25^{\circ} \mathrm{S}$, and $30^{\circ}$ to $60^{\circ} \mathrm{E}$; total relief $\sim 3 \mathrm{~km}$. 
Martian "volcanoes" are often said to resemble Hawaii. But these broad, circular, single-peak structures do not resemble Hawaii at all.
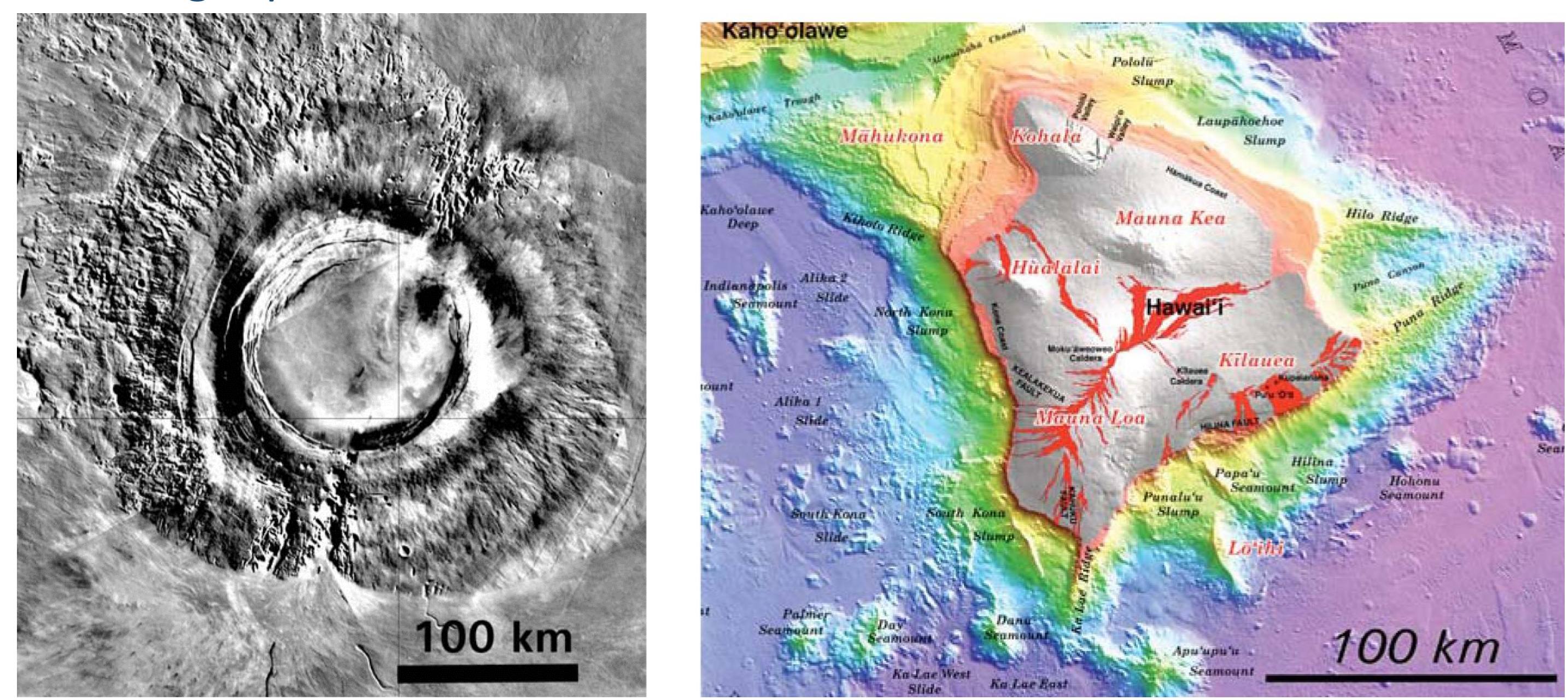

Fig. 23. Martian impact-melt construct Arsia Mons compared with Hawaii. Each rises 9 km from its base, Arsia from Tharsis plateau, Hawaii from Pacific Ocean floor. Top: Arsia Mons "volcano". Its huge, shallow, circular caldera is as large as irregular Hawaii is above sea level and sagged into an enormous mass of shallow melt. Arsia is centered at $\sim 9^{\circ} \mathrm{S}, 239^{\circ} \mathrm{E}$; composite Viking Orbiter imagery by USGS. Bottom: island of Hawaii, gray above sea level; historic lava flows, mostly erupted from dikes along gravitationally widening lateral rifts, are in red; ocean depths are colored deepening to magenta and are $\sim 5.5 \mathrm{~km}$ deep. Hawaii is a composite of five volcanoes at the surface and grew by frequent small increments of magma over a few million years. Shallow subsurface melt never covered a large area and the largest caldera is only $\sim 4 \mathrm{~km}$ across. Edges of map: $154^{\circ}$ and $157^{\circ} \mathrm{W}$, and $18.5^{\circ}$ and $20.5^{\circ} \mathrm{N}$; map from Eakins et al. (2003). The assumptions that Martian "volcanoes" closely resemble Hawaii, and that

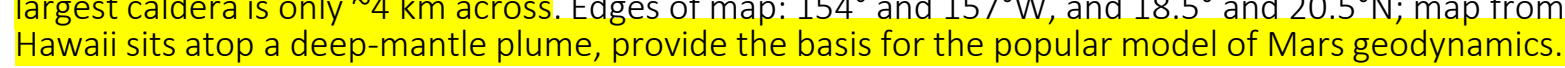




\section{Known ages of some features associated with plate tectonics (after Stern et al. 2016), provide evidence that plate tectonics began about $600 \mathrm{Ma}$.}

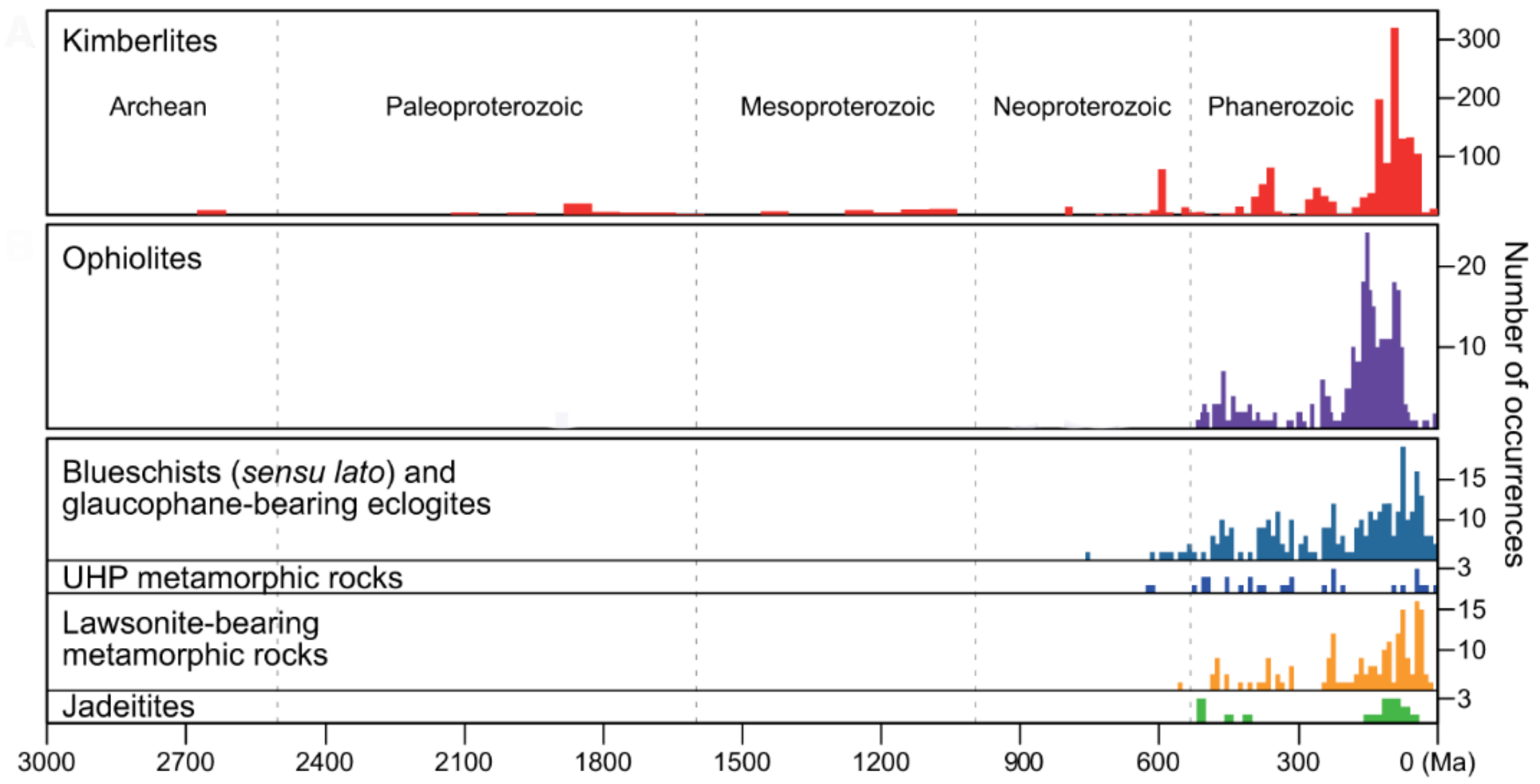

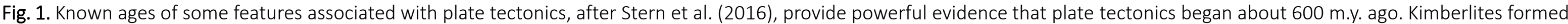

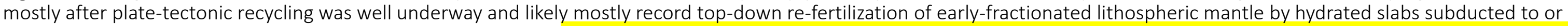

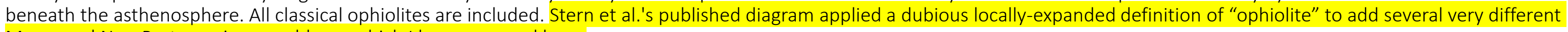
Meso- and Neo-Proterozoic assemblages which I have removed here. 
- The approximate coincidence of the Ediacaran biological leap with the onset of plate tectonics makes a connection between them possible.

- The link may be that Earth's asthenosphere and strong dipolar magnetic field both originated then, as a result of torques and frictional heating from Sun/Earth/Moon orbital mechanics.

- Asthenosphere enabled plate tectonics, and influenced convection in the outer core.

- This in turn allowed differential core motions and development of an inner core and internal strong dipolar magnetic field, shielding Earth's surface and enabling evolution. 
Recent advances in orbital understanding and paleomagnetic evidence suggest such speculative ideas.

But much more information of course is needed to test them. 
Why does Earth have plate tectonics, while Venus and Mars do not? In this paper he was coming around to a view that the elephant in the room is the Moon.

Also: If Earth, Venus \& Mars received oceanic quantities of water through impacts $\sim 4 \mathrm{Ga}$, the Moon likely did so as well giving rise to its own short-lived seas. 